seizures (Proc Soc Exp Biol Med. 1966;123:968), refer to WF Petersen's extensive treatise concerning effects of weather on disease and the relation between meteorological disturbances and onset and severity of epilepsy (1934). Also, Tille D had observed a higher incidence of febrile convulsions related to cold weather fronts (1950).

\title{
NON-BENIGN FAMILIAL NEONATAL CONVULSIONS
}

An electroclinical pattern characteristic of benign familial neonatal convulsions is reported in two neonates with non-benign seizures treated at the Miami Children's Hospital, FL. Ten seizures recorded by continuous videoEEG telemetry began with generalized tonic posturing and diffuse attenuation of EEG activity. Bilateral clonic movements that followed were accompanied by repetitive sharp waves or spikes. None had a family history of seizures, and one patient followed for 5 years had speech delay, hypotonia, hyperreflexia, and autistic behavior. The cause of seizures was undetermined. (Alfonso I, Hahn JS, Papazian $O$ et al. Bilateral tonic-clonic epileptic seizures in nonbenign familial neonatal convulsions. Pediatr Neurol April 1997;16:249-251). (Respond: Dr Alfonso, Department of Neurology, 3200 SW 60th Court, Suite 302, Miami, FL $33155)$.

COMMENT. The electroclinical events thought to be characteristic of benign familial neonatal convulsions (BFNC) are nonspecific. BFNC is heterogeneous in clinical and EEG features and cannot be distinguished from benign infantile familial convulsions on the basis of clinical seizure patterns. (see Progress in Pediatric Neurology III, 1997;pp8-9).

Outcome of neonates with electrographically identified seizures was correlated with background EEG and number of independent seizure foci in a study of 53 neonates at Sydney Children's Hospital, Australia (Bye AME et al. Pediatr Neurol April 1997;16:225-231). A severely depressed EEG background in a neonate with seizures or at risk of seizures was correlated with mortality during the first month, and frequent neonatal independent seizure foci correlated with poor outcome at 1 year.

\section{HANDICAPS ASSOCIATED WITH EPILEPSY}

The prevalence and severity of handicaps in 217 children and adolescents with epilepsy were assessed at the University of Goteborg, Ostra Hospital, Sweden, using the World Health Organization International Classification of Impairments, Disabilities and Handicaps (ICIDH). Major additional disorders occurred in 113 (52\%), mental retardation (MR) in 106 and cerebral palsy (CP) in 48 children. Motor and sensory disabilities, involving locomotion, arm and hand function, were common even in children unaffected by CP or MR. Handicap, defined as a disadvantage, resulting from a disability or impairment, adversely affected physical independence and orientation, correlated with epilepsy duration and secondary generalization, and was relieved by epilepsy surgery. (Beckung E, Uvebrant P. Impairments, disabilities and handicaps in children and adolescents with epilepsy. Acta Paediatr March 1997;86:254-260). (Respond: Dr E Beckung, Department of Paediatrics, University of Goteborg, Ostra Hospital, S-41685 Goteborg, Sweden).

COMMENT. Children with epilepsy complicated by cerebral palsy or mental retardation are diagnosed and treated early for their associated disabilities and handicaps. Those with epilepsy unassociated with CP or MR 
frequently have disabilities and handicaps in mobility and physical independence that are often untreated. The prompt recognition and rehabilitation of impairments of coordination, balance, fine motor and sensory function should prevent development of handicap in these patients.

Self-esteem, behavior, and concerns surrounding epilepsy in siblings of children with epilepsy were investigated by the Minnesota Epilepsy Group, St Paul, MN. (Mims J. I Child Neurol April 1997;12:187-192). Families of children with frequent seizures had significantly more stress, but no loss of self-esteem or socialization. The effects of epilepsy on the siblings of children with intractable seizures should receive further study.

\section{ATTENTION DEFICIT HYPERACTIVITY DISORDER}

\section{TWIN STUDIES OF ADHD}

Genetic and environmental contributions to the inattention and impulsivity-hyperactivity associated with ADHD in 576 twin boys, aged 11 and 12 years, participants in the Minnesota Twin Family Study, were estimated by teacher ratings and maternal interviews in a report from the Department of Psychology and the Institute of Human Genetics, University of Minnesota, Minneapolis. Univariate analyses of the teacher and maternal reports confirmed the importance of genetic factors in the mediation of both inattention and hyperactivity-impulsivity subtypes of ADHD. For both traits, the genetic factor was considerably higher for maternal reports, which suggests a rater bias. Environmental factors, shared or nonshared among family members, had lesser contributions to the etiology of ADHD, and shared environment affected only the teacher-rated inattention dimension. (Sherman DK, Iacono WG, McGue MK. Attention-deficit hyperactivity disorder dimensions: a twin study of inattention and impulsivity-hyperactivity. I Am Acad Child Adolesc Psychiatry June 1997;36:745-753). (Reprints: Dt lacono, Department of Psychology, University of Minnesota, Elliott Hall, 75 East River Road, Minneapolis, MN 55455).

COMMENT. Twin studies involving only males suggest that genetic factors are important in the cause of both inattention and hyperactivityimpulsivity subtypes of ADHD. Environmental experiences may exert a lesser effect on the development of these traits. The mode of inheritance of ADHD is undetermined, and results in affected girls, who characteristically demonstrate a greater degree of inattention, may be different. The inclusion of multiple informants, including psychologists and physicians, both neurologists and psychiatrists, would tend to lessen the influence of bias in studies involving ratings.

The extent of the genetic influence in the cause of ADHD varies according to the informant source. (Sherman DK, McGue MK, Iacono WG. Twin concordance for attention deficit hyperactivity disorder: a comparison of teachers' and mothers' reports. Am I Psychiatry April 1997;154:532-535). Environmental organic factors in etiology may receive greater emphasis and recognition among patients attending for pediatric neurology evaluation.

ADHD is a continuum, not a discrete entity, according to a large twin study, involving almost 2000 families recruited from the Australian MRC Twin Registry, and reported from the Prince of Wales Hospital, Randwick, NSW 